Review

\title{
Interventions to Support Integrated Psychological Care and Holistic Health Outcomes in Paediatrics
}

\author{
Roz Shafran * (D), Sophie D. Bennett and Mhairi McKenzie Smith \\ UCL Great Ormond Street Institute of Child Health, 30 Guilford St., London WC1N 1EH, UK; \\ Sophie.bennett.10@ucl.ac.uk (S.D.B.); mhairi.mckenzie.16@ucl.ac.uk (M.M.S.) \\ * Correspondence: r.shafran@ucl.ac.uk; Tel.: +44-(0)-20-7905-2000
}

Academic Editors: Deborah Christie and Gail Dovey-Pearce

Received: 7 July 2017; Accepted: 7 August 2017; Published: 16 August 2017

\begin{abstract}
There are strong calls from many national and international bodies for there to be a 'holistic' and integrated approach to the understanding and management of psychological and physical health needs. Such holistic approaches are characterized by the treatment of the whole person, taking into account mental and social factors, rather than just the symptoms of a disease. Holistic approaches can impact on mental and physical health and are cost-effective. Several psychological interventions have demonstrated efficacy in improving holistic health outcomes, for example Cognitive Behaviour Therapy, Behavioural Therapies and Problem Solving Therapies. They have shown to impact upon a wide range of outcomes, including psychological distress, pain, physical health, medication adherence, and family outcomes. There is increasing recognition that the holistic goals of the child and family should be prioritised, and that interventions and outcomes should reflect these goals. A focus on holistic goals in therapy can be achieved through a combination of personalised goal-based outcomes in addition to symptom-based measures.
\end{abstract}

Keywords: psychological intervention; goal based outcomes; paediatrics

\section{The Benefits of Integrated Psychological Care}

There is an unfortunate and longstanding tradition of considering the mind and body as separate and distinct entities. Such separation or 'dualism' is typically attributed to the philosopher René Descartes (1596-1650), although there is debate as to his exact position regarding the implications of this for health [1]. It has taken until the late 20th and early 21st Centuries for there to be strong calls for there to be a 'holistic' and integrated approach to the understanding and management of psychological and physical health needs. Such holistic approaches are characterized by the treatment of the whole person, taking into account mental and social factors, rather than just the symptoms of a disease.

There are several reasons for the movement towards an integrated approach to psychological care and physical health. First and foremost, having a long term physical condition greatly increases the risk of experiencing psychological distress [2-4]. Two of the most common and typical childhood chronic illnesses associated with elevated psychological disorders are epilepsy and Type 1 diabetes. In the classic community Isle of Wight study, $29 \%$ of children with epilepsy had at least one psychological disorder, over four times the rate in the general population [5]. In diabetes clinics, $47 \%$ of children were found to develop significant psychological needs at 10-year follow-up [6].

The mechanisms of this relationship are not fully understood; physical and psychological conditions may share the same pathology [7], or the stress associated with having a long-term condition and its treatment may affect psychological functioning [8]. In children, a long-term illness may impact on all domains of development and functioning across the age range including social development, separation from the family of origin, individuation, developmental tasks, resilience and having a sense of identity away from the illness [9-12]. 
In addition to the impact of a chronic illness on psychological functioning, psychological distress may impact upon the chronic illness. For instance, psychological distress may lead to poor treatment compliance, which exacerbates the physical condition, and impairs self-management and worsens long-term outcome [13]; depression in children with diabetes is associated with poorer blood sugar control [14] and in turn with later retinal damage [15]. Psychological disorders have been associated with increased seizure frequency in juvenile myoclonic epilepsy [16]. Overall, serious psychological disturbance has the same effect on life-expectancy as smoking, and more than obesity [17]. This has been partly attributed to psychological distress intensifying the effects of physical illness through physiological responses. For example, psychological distress may increase the production of stress hormones such as cortisol, which may undermine the immune system [17].

A second, less scientific but highly pragmatic reason for the move towards integrated healthcare is the recognition of the financial cost of having both a physical and psychological health need. In adults, Co-morbid mental health disorders increase costs for long term conditions (LTCs) by $45 \%$ per person [18]. This means that roughly $£ 1$ in every $£ 8$ spent on LTCs is connected to poor mental health, equating to $£ 8-13$ billion of NHS spending in England each year [18]. Psychological interventions have significant clinical and cost benefits. Meta-analyses indicate that psychological interventions reduce care costs by $20 \%$ [19], equating to $£ 1235$ per case, and that the cost of psychological treatment is more than offset by the resulting savings in physical healthcare costs [18]. Considering psychological distress in the context of chronic illness, cognitive behaviour therapy (CBT)-based interventions can improve treatment adherence, psychosocial adjustment, coping skills and quality of life for people with co-morbid LTCs, as well as reducing use of health care services [20,21]; including a psychological component in a breathlessness clinic for Chronic Obstructive Pulmonary Disease (COPD) in adults led to 1.17 fewer A\&E presentations and 1.93 fewer hospital bed days per person in the six months after the intervention, which translated into savings of $£ 837$ per person [22].

Not only are there cost-savings in relation to having both a physical and mental health condition, but in addition, for children and young people, there are savings related to early intervention and reducing costs across the lifespan. For example, a child with conduct disorder at 10 subsequently costs the government roughly $£ 100,000$ more than other children throughout his/her lifespan [23]. Having a mental health disorder by the age of 16 is associated with $19 \%$ lower family income at age 23 , equating to an estimated $£ 388,000$ across the lifespan [24]. Overall, there are high potential cost savings for treating young people with mental health disorders and LTCs since the strategies learnt in youth for reducing mental health difficulties can be applied throughout the lifespan with widespread clinical, social and occupational benefits [25].

\section{Evidence for Interventions to Support Integrated Psychological Care}

Whilst there has been extensive research on the development and evaluation of psychological interventions aimed specifically to treat emotional distress in young people [26], very few studies have examined their use in populations with a chronic illness [27]. There is ongoing research as to the nature of the distress that arises in relation to having a long-term condition; specifically, (a) whether the distress is qualitatively different from that seen in other contexts (i.e., anxiety or low mood in children who do not have a chronic illness); and (b) whether any differences are phenomenological in nature or whether they are fundamental, such that standard psychological treatments shown to work for young people with psychological needs in the absence of long term illness require significant adaptation-i.e., modification throughout the intervention to account for the presence of a chronic illness [28-30].

The debate about the degree of 'adaptation' cuts across the range of different psychological treatment approaches that are used to help people with emotional distress. This is because although there are important differences in psychological treatment approaches, they also have much in common. Psychological treatment approaches all aim to help the young person and/or their families better understand and manage their distress (or behaviour), participate in developmentally appropriate 
activities that they could not previously engage in and ultimately help the young person to function better in the world around them. Within the range of psychological treatments, some have more scientific support than others and hence are recommended by bodies such as NICE.

However, it is important to bear in mind the distinction between 'evidence of absence' in which there is evidence the psychological treatment is not helpful (or is harmful) and 'absence of evidence' in which there is insufficient research to be able to establish the effectiveness of the intervention. Examples of areas in which there is research regarding the use of psychological interventions include interventions for mental health, chronic pain, procedural pain/anxiety and medication adherence. Each of these areas are expanded on in turn below.

\subsection{Mental Health}

Systematic reviews have demonstrated that there is a lack of evidence regarding interventions for significant emotional distress in children and young people with a chronic physical illness [27]. The evidence that is available suggests that these children may benefit from cognitive behavioural interventions for depression and anxiety. Such interventions may improve psychological distress, although there is little evidence that they improve physical health outcomes in children [27].

Cognitive behavioural interventions centre around changing unhelpful thoughts and behaviours; specifically, they involve identifying and challenging unhelpful thoughts/thinking patterns; cognitive restructuring to change behaviour in response to these thoughts and practice of desirable behaviours. Whilst CBT interventions may be manualised, this does not equate to a rigid, 'one-size fits all' approach. Rather such interventions consider 'flexibility with fidelity' [31], in other words the core components of the intervention are followed, but therapists must consider the goals and outcomes of importance to the client and be responsive to their needs. Such goals may focus on wider holistic needs, for example, being able to visit friends' houses, in addition to purely symptom-based measures (such as depression or anxiety severity).

Considering the issue of adaptation, some CBT interventions have been modified to account for the presence of a chronic illness, with illness-specific content (e.g., CBT for anxiety in young people with Inflammatory Bowel Disease [32]); whereas others have not altered the content [33]. Regarding integration of physical and psychological healthcare, whilst many studies did not adapt or modify the content of interventions to account for the presence of chronic illness, several CBT studies allowed for more flexible delivery through offering telephone sessions, or sessions at home/the medical treatment location.

One reason for reviews demonstrating a lack of evidence in this area may be that mental health clinicians are concerned about the safety of these interventions in a population with chronic illness. For example, one of the key elements of CBT for anxiety is exposure to the feared stimulus. Clinicians may be concerned about causing undue distress to a child who is already physically unwell, and potentially causing a worsening of the physical health symptoms, for example triggering an attack in a child with asthma or seizure in a child with epilepsy. A key element of ensuring integrated, holistic care in these interventions is through close liaison between the psychology/mental health team and the physical healthcare team, for example through joint assessments and integrated treatment plans, consulting with the paediatrician where appropriate. In addition, lack of evidence may reflect the inclusion criteria of reviews undertaken to date, which have focused on interventions aimed at reducing psychological distress. In addition to the studies explored in these reviews, it may be that some psychological interventions designed primarily to treat an issue other than emotional distress, for example those focused on medication adherence, may also affect psychological outcomes; however, research studies of these interventions generally do not investigate cohorts of children with elevated levels of emotional distress. 


\subsection{Chronic Pain}

The close integration between physical and psychological healthcare is exemplified by the research on the management of the pain that often accompanies the physical health condition. Core Standards for Pain Management Services in the UK [34] stipulate that children with chronic pain should be offered psychological intervention in addition to pharmacological and physical treatments, owing to the well-established biopsychosocial models of chronic pain [35] and the large number of randomised controlled trials that convincingly demonstrate the positive impact of psychological intervention on pain and broader functioning [36,37]. Interventions for pain include CBT, relaxation training/biofeedback, and Exposure and Acceptance based therapies, such as Acceptance and Commitment Therapy (ACT [38]). Relaxation training involves teaching relaxation strategies/techniques such as progressive muscle relaxation, breathing techniques and/or imagery. In addition, biofeedback may be used, in which monitors are placed to record biological indicators of stress/anxiety, such as muscle activity, heart rate, or breathing rate. This is used to increase awareness of the stress response, and the effect of relaxation exercises on this response. ACT interventions promote the acceptance of negative thoughts or feelings (e.g., pain, negative emotions) and engagement in activities that are meaningful to the person, even when this may trigger negative thoughts/feelings. For example, in pain interventions, a child may be encouraged to partake in activities that are meaningful to them, even if they cause pain. The child then gradually distances themselves from pain and pain has a lesser impact on their behaviours and therefore life [39]. Psychological interventions for pain have been shown to have a positive effect on both pain and disability, but outcomes on psychological distress are less clear [37]. A review of psychological interventions for parents of children and young people with a chronic physical illness found good evidence for the effectiveness of interventions that included parents for reducing pain, but not other outcomes such as psychological distress, in children with chronic pain [40].

\subsection{Procedural Pain, Distress and Anxiety}

Distraction (for example through toys or games) and hypnosis have been demonstrated to reduce needle-pain and distress [41]. A recent review found no evidence to support the efficacy of educational interventions (preparation and information), CBT, parent coaching or virtual reality on needle related pain and distress [42]. However, this may be a separate issue from a needle phobia, in which a child or young person may worry and/or have significant fear in advance of a procedure. Phobias of procedures, including venepuncture, may be particularly impairing for those with chronic illness, and may affect physical health, through cancellations of operations, or poorer adherence to medical regimes. For example, in children with diabetes, a greater fear of needles has been associated with higher $\mathrm{HbA1c}$ levels and less frequent blood sugar monitoring [43]. One-session exposure interventions have demonstrated efficacy in treating phobias in adults, and their effectiveness has recently been demonstrated in a trial for blood-injection-injury phobia in children and young people [44].

\subsection{Adherence}

Several reviews have demonstrated the efficacy of psychological interventions for improving adherence to medications/compliance with a medical regime [45,46], which has implications for physical wellbeing. Interventions commonly include behavioural (interventions with a focus on behaviour change) or cognitive-behavioural, and may include family elements. Motivational interviewing, which uses conversation to help a person consider their ambivalence towards a particular behaviour (e.g., adhering to medication regimes), and ways in which that behaviour is in line with a person's current values and future goals (e.g., being able to participate in sports) may be used with adolescents [47]. A meta-analysis [48] demonstrated medium effect sizes for behavioural and multi-component interventions, which involved a combination of one or more of social-support, social skills training, family therapy and a behavioural or educational component. Conversely, educational 
interventions alone and broader psychosocial interventions alone, which were focused around family functioning or crisis intervention but not on the adherence behaviour per se, only demonstrated small effect sizes. Technology-based interventions, such as games or glucose meters, did not demonstrate any significant effect overall; these were delivered without ongoing guidance or clinical support. As treatment adherence reduces from childhood to adolescence [49] and young people have stated a preference for technology based interventions [50], future research may benefit from enhancing efficacy of such interventions, perhaps through combining them with clinician support.

\subsection{Wider Family Outcomes}

Family based interventions have demonstrated efficacy across a range of childhood chronic illnesses. In addition to positive effects on child outcomes, Problem Solving Therapy which includes parents has been demonstrated to improve parental mental health [40]. Problem Solving Therapy [51] involves teaching a person a structured way to identify specific problems causing them distress, identify potential solutions, and evaluate the outcome of the chosen solution, thereby promoting self-efficacy, although interventions targeted directly at parental mental health have had inconclusive findings [40]. Other family based interventions include family therapy (FT) and Multisystemic Therapy (MST). Such interventions consider that social relationships between people and contexts cause and maintain problematic behaviour, and the focus of the intervention is therefore on these relationships; MST is an intensive home-based therapy considering the family and relationships with wider systems (such as school). The overall efficacy of family based therapies on parent and child outcomes is unclear [40].

\section{Holistic Health Care Outcomes and what Matters to Patients}

The above review of the literature makes it clear that there are a wide range of health outcomes that are amenable to psychological intervention, ranging from psychological distress to physical health outcomes, or adherence to a medical regime. However specific studies/interventions often focus on one primary outcome and this may not be reflective of the outcomes of primary importance to patients or families. For example, the little research available on the treatment of psychological distress in the context of a long-term condition has typically used a specific, symptom-based measure to assess the impact of the intervention. Such measures often do not capture the broader holistic goals of therapy in terms of helping the young person function better in the world around them and continue along the developmental trajectory; it may be more meaningful for a young person to be able to attend after-school activities, than reduce their symptom-count on a depression severity measure, for example. With the advent of targets to demonstrate the impact of our interventions on patients, the challenge is how to choose the correct metric to demonstrate the benefit to patients and their families. Symptom-based measures are clearly necessary but they are also likely to be insufficient [52] which is why psychological services also use goal-based measures to allow for personalisation of treatment outcomes [53]. In addition, the specific intervention chosen should reflect the evidence-base for the goals of the child and family, considering the outcomes that are most important to them. For example, if the primary goal is pain reduction, then an ACT-based intervention may be appropriate, but if it is to reduce anxiety, then a CBT intervention (as recommended by NICE [54]) may be more effective.

\section{The Way Forward}

Overall, this review highlights several psychological interventions for children and young people who have a chronic illness that have demonstrated efficacy across a range of areas, including pain, mental health, procedural anxiety, adherence to a medical regime and wider family outcomes. Integrating psychological care within the paediatric setting is therefore essential if we are to improve holistic patient outcomes. Adult studies also suggest that such an approach is cost effective. Young people and their families want this type of joined-up approach to their healthcare. At its very simplest, this may mean coordinating appointments with separate psychology and paediatric services or offering 
co-located services, to minimise travel and time burden. At its most sophisticated, it would mean having systems to identify psychological needs early in the process and to personalise the psychological intervention to both the individual and family characteristics, as well as the characteristics of the long-term condition [55]. Such personalisation would, by necessity, capture the outcomes that were most meaningful and important to the young person and the family as well as standardised outcomes that allow clinicians and researchers to benchmark progress and ensure minimisation of harm. We are living in exciting and changing times where, finally, the voice of the young person and the family is being prioritised Such personalisation through listening to the goals and aims of the family is the key to holistic health outcomes that reflect the full potency and benefit of an integrated healthcare approach.

Acknowledgments: No funding was received for completion of this review. The research was supported by the National Institute for Health Research Biomedical Research Centre at Great Ormond Street Hospital for Children NHS Foundation Trust and University College London.

Author Contributions: All authors contributed to the writing of this review and reviewed the final manuscript.

Conflicts of Interest: The authors declare no conflicts of interest.

\section{References}

1. Duncan, G. Mind-body dualism and the biopsychosocial model of pain: What did Descartes really say? J. Med. Philos. 2000, 25, 485-513. [CrossRef]

2. Pinquart, M.; Shen, Y. Depressive symptoms in children and adolescents with chronic physical illness: An updated meta-analysis. J. Pediatr. Psychol. 2011, 36, 375-384. [CrossRef] [PubMed]

3. Pinquart, M.; Shen, Y. Behavior problems in children and adolescents with chronic physical illness: A meta-analysis. J. Pediatr. Psychol. 2011, 36, 1003-1016. [CrossRef] [PubMed]

4. Pinquart, M.; Shen, Y. Anxiety in children and adolescents with chronic physical illnesses: A meta-analysis. Acta Paediatr. 2011, 100, 1069-1076. [CrossRef] [PubMed]

5. Rutter, M.; Graham, P.J.; Yule, W. A Neuropsychiatric Study in Childhood (No. 6); Heinemann Educational Books: London, UK, 1970.

6. Kovacs, M.; Goldston, D.; Obrosky, D.S.; Bonar, L.K. Psychiatric disorders in youths with IDDM: Rates and risk factors. Diabetes Care 1997, 20, 36-44. [CrossRef] [PubMed]

7. Kanner, A.M. Psychiatric issues in epilepsy: The complex relation of mood, anxiety disorders, and epilepsy. Epilepsy Behav. 2009, 15, 83-87. [CrossRef] [PubMed]

8. Golden, S.H.; Lazo, M.; Carnethon, M.; Bertoni, A.G.; Schreiner, P.J.; Roux, A.V.D.; Lyketsos, C. Examining a bidirectional association between depressive symptoms and diabetes. JAMA 2008, 299, 2751-2759. [CrossRef] [PubMed]

9. Lambert, V.; Keogh, D. Striving to live a normal life: A review of children and young people's experience of feeling different when living with a long term condition. J. Pediatr. Nurs. 2015, 30, 63-77. [CrossRef] [PubMed]

10. Luyckx, K.; Seiffge-Krenke, I.; Schwartz, S.J.; Goossens, L.; Weets, I.; Hendrieckx, C.; Groven, C. Identity development, coping, and adjustment in emerging adults with a chronic illness: The sample case of type 1 diabetes. J. Adolesc. Health 2008, 43, 451-458. [CrossRef] [PubMed]

11. Michaud, P.A.; Suris, J.C.; Viner, R. The adolescent with a chronic condition: Epidemiology, developmental issues and health care provision. In WHO Discussion Papers on Adolescence; WHO: Geneva, Switzerland, 2007. Available online: http://apps.who.int/iris/bitstream/10665/43775/1/9789241595704_eng.pdf (accessed on 10 August 2017).

12. Pinquart, M.; Teubert, D. Academic, physical, and social functioning of children and adolescents with chronic physical illness: A meta-analysis. J. Pediatr. Psychol. 2012, 37, 376-389. [CrossRef] [PubMed]

13. Lustman, P.J.; Clouse, R.E. Depression in diabetic patients: The relationship between mood and glycemic control. J. Diabetes Complicat. 2005, 19, 113-122. [CrossRef] [PubMed]

14. Hood, K.K.; Huestis, S.; Maher, A.; Butler, D.; Volkening, L.; Laffel, L.M. Depressive symptoms in children and adolescents with type 1 diabetes. Diabetes Care 2006, 29, 1389. [CrossRef] [PubMed]

15. Kovacs, M.; Mukerji, P.; Drash, A.; Iyengar, S. Biomedical and psychiatric risk factors for retinopathy among children with IDDM. Diabetes Care 1995, 18, 1592-1599. [CrossRef] [PubMed] 
16. De Araujo Filho, G.M.; Yacubian, E.M.T. Juvenile myoclonic epilepsy: Psychiatric comorbidity and impact on outcome. Epilepsy Behav. 2013, 28, S74-S80. [CrossRef] [PubMed]

17. Centre for Economic Performance. How Mental Illness Loses Out in the NHS. 2012. Available online: http:/ / cep.lse.ac.uk/pubs/download/special/cepsp26.pdf (accessed on 10 August 2017).

18. Naylor, C.; Parsonage, M.; McDaid, D.; Knapp, M.; Fossey, M.; Galea, A. Long-Term Conditions and Mental Health: The Cost of Comorbidities. 2012. Available online: https://www.kingsfund.org.uk/sites/default/ files / field/field_publication_file/long-term-conditions-mental-health-cost-comorbidities-naylor-feb12. pdf (accessed on 10 August 2017).

19. Chiles, J.A.; Lambert, M.J.; Hatch, A.L. The impact of psychological interventions on medical cost offset: A metaanalytic review. Clin. Psychol. Sci. Pract. 1999, 6, 204-220. [CrossRef]

20. Thompson, R.D.; Delaney, P.; Flores, I.; Szigethy, E. Cognitive-behavioral therapy for children with comorbid physical illness. Child Adolesc. Psychiatr. Clin. N. Am. 2011, 20, 329-348. [CrossRef] [PubMed]

21. Spurgeon, P.; Hicks, C.; Barwell, F.; Walton, I.; Spurgeon, T. Counselling in primary care: A study of the psychological impact and cost benefits for four chronic conditions. Eur. J. Psychother. Couns. Health 2005, 7, 269-290. [CrossRef]

22. Howard, C.; Dupont, S.; Haselden, B.; Lynch, J.; Wills, P. The effectiveness of a group cognitive-behavioural breathlessness intervention on health status, mood and hospital admissions in elderly patients with chronic obstructive pulmonary disease. Psychol. Health Med. 2010, 15, 371-385. [CrossRef] [PubMed]

23. Scott, S.; Knapp, M.; Henderson, J.; Maughan, B. Financial cost of social exclusion: Follow up study of antisocial children into adulthood. BMJ 2001, 323, 191. [CrossRef] [PubMed]

24. Goodman, A.; Joyce, R.; Smith, J.P. The long shadow cast by childhood physical and mental problems on adult life. Proc. Natl. Acad. Sci. USA 2011, 108, 6032-6037. [CrossRef] [PubMed]

25. Chief Medical Officer's Annual Report. Our Children Deserve Better: Prevention Pays; Department of Health: London, UK, 2012. Available online: https: / www.gov.uk/government/publications / chief-medicalofficers-annual-report-2012-our-children-deserve-better-prevention-pays (accessed on 10 August 2017).

26. Chorpita, B.F.; Daleiden, E.L.; Ebesutani, C.; Young, J.; Becker, K.D.; Nakamura, B.J.; Smith, R.L. Evidence-based treatments for children and adolescents: An updated review of indicators of efficacy and effectiveness. Clin. Psychol. Sci. Pract. 2011, 18, 154-172. [CrossRef]

27. Bennett, S.; Shafran, R.; Coughtrey, A.; Walker, S.; Heyman, I. Psychological interventions for mental health disorders in children with chronic physical illness: A systematic review. Arch. Dis. Child. 2015, 100, 308-316. [CrossRef] [PubMed]

28. Dudeney, J.; Sharpe, L.; Sicouri, G.; Lorimer, S.; Dear, B.F.; Jaffe, A.; Hunt, C. Attentional Bias in Children with Asthma with and without Anxiety Disorders. J. Abnorm. Child Psychol. 2017, 1-12. [CrossRef] [PubMed]

29. Pao, M.; Bosk, A. Anxiety in medically ill children/adolescents. Depression Anxiety 2011, 28, 40-49. [CrossRef] [PubMed]

30. Szigethy, E.M.; Youk, A.O.; Benhayon, D.; Fairclough, D.L.; Newara, M.C.; Kirshner, M.A.; Keljo, D.J. Depression subtypes in pediatric inflammatory bowel disease. J. Pediatr. Gastroenterol. Nutr. 2014, 58, 574. [CrossRef] [PubMed]

31. Kendall, P.C.; Gosch, E.; Furr, J.M.; Sood, E. Flexibility within fidelity. J. Am. Acad. Child Adolesc. Psychiatry 2008, 47, 987-993. [CrossRef] [PubMed]

32. Reigada, L.C.; Benkov, K.J.; Bruzzese, J.M.; Hoogendoorn, C.; Szigethy, E.; Briggie, A.; Warner, C.M. Integrating illness concerns into cognitive behavioral therapy for children and adolescents with inflammatory bowel disease and co-occurring anxiety. J. Spec. Pediatr. Nurs. 2013, 18, 133-143. [CrossRef] [PubMed]

33. Blocher, J.B.; Fujikawa, M.; Sung, C.; Jackson, D.C.; Jones, J.E. Computer-assisted cognitive behavioral therapy for children with epilepsy and anxiety: A pilot study. Epilepsy Behav. 2013, 27, 70-76. [CrossRef] [PubMed]

34. Royal College of Anaesthetists. Core Standards for Pain Management Services in the UK; Royal College of Anaesthetists: London, UK, 2015. Available online: http:/ / www.rcoa.ac.uk/system/files/FPM-CSPMSUK2015.pdf (accessed on 10 August 2017).

35. Varni, J.W.; Bessman, C.A.; Russo, D.C.; Cataldo, M.F. Behavioral management of chronic pain in children. Arch. Phys. Med. Rehabil. 1980, 61, 375-379. [PubMed] 
36. Eccleston, C.; Palermo, T.M.; Williams, A.; Lewandowski, A.; Morley, S. Psychological therapies for the management of chronic and recurrent pain in children and adolescents. Cochrane Database Syst. Rev. 2009, 2. [CrossRef]

37. Fisher, E.; Heathcote, L.; Palermo, T.M.; de C Williams, A.C.; Lau, J.; Eccleston, C. Systematic review and meta-analysis of psychological therapies for children with chronic pain. J. Pediatr. Psychol. 2014, 39, 763-782. [CrossRef] [PubMed]

38. Hayes, S.C.; Strosahl, K.D.; Wilson, K.G. Acceptance and Commitment Therapy: An Experiential Approach to Behavior Change; Guilford Press: New York, NY, USA, 1999.

39. Wicksell, R.K.; Melin, L.; Lekander, M.; Olsson, G.L. Evaluating the effectiveness of exposure and acceptance strategies to improve functioning and quality of life in longstanding pediatric pain-A randomized controlled trial. Pain 2009, 141, 248-257. [CrossRef] [PubMed]

40. Eccleston, C.; Fisher, E.; Law, E.; Bartlett, J.; Palermo, T.M. Psychological interventions for parents of children and adolescents with chronic illness. Cochrane Database Syst. Rev. 2015, 4. [CrossRef]

41. Uman, L.S.; Chambers, C.T.; McGrath, P.J.; Kisely, S. Psychological interventions for needle-related procedural pain and distress in children and adolescents. Cochrane Database Syst. Rev. 2006, 4. [CrossRef]

42. Taddio, A.; McMurtry, C.M. Psychological interventions for needle-related procedural pain and distress in children and adolescents. Paediatr. Child Health 2015, 20, 195. [CrossRef] [PubMed]

43. Cemeroglu, A.; Can, A.; Davis, A.; Cemeroglu, O.; Kleis, L.; Daniel, M.; Koehler, T. Fear of needles in children with type 1 diabetes mellitus on multiple daily injections and continuous subcutaneous insulin infusion. Endocr. Pract. 2014, 21, 46-53. [CrossRef] [PubMed]

44. Oar, E.L.; Farrell, L.J.; Waters, A.M.; Conlon, E.G.; Ollendick, T.H. One session treatment for pediatric blood-injection-injury phobia: A controlled multiple baseline trial. Behav. Res. Ther. 2015, 73, 131-142. [CrossRef] [PubMed]

45. Pai, A.L.; McGrady, M. Systematic review and meta-analysis of psychological interventions to promote treatment adherence in children, adolescents, and young adults with chronic illness. J. Pediatr. Psychol. 2014, 39, 918-931. [CrossRef] [PubMed]

46. Dean, A.J.; Walters, J.; Hall, A. A systematic review of interventions to enhance medication adherence in children and adolescents with chronic illness. Arch. Dis. Child. 2010, 95, 717-723. [CrossRef] [PubMed]

47. Erickson, S.J.; Gerstle, M.; Feldstein, S.W. Brief interventions and motivational interviewing with children, adolescents, and their parents in pediatric health care settings: A review. Arch. Pediatr. Adolesc. Med. 2005, 159, 1173-1180. [CrossRef] [PubMed]

48. Kahana, S.; Drotar, D.; Frazier, T. Meta-analysis of psychological interventions to promote adherence to treatment in pediatric chronic health conditions. J. Pediatr. Psychol. 2008, 33, 590-611. [CrossRef] [PubMed]

49. Ellis, D.A.; Frey, M.A.; Naar-King, S.; Templin, T.; Cunningham, P.; Cakan, N. Use of multisystemic therapy to improve regimen adherence among adolescents with type 1 diabetes in chronic poor metabolic control. Diabetes Care 2005, 28, 1604-1610. [CrossRef] [PubMed]

50. Frøisland, D.H.; Årsand, E.; Skårderud, F. Improving diabetes care for young people with type 1 diabetes through visual learning on mobile phones: Mixed-methods study. J. Med. Internet Res. 2012, 14, e111. [CrossRef] [PubMed]

51. Nezu, A.M.; Nezu, C.M. Problem solving therapy. J. Psychother. Integr. 2001, 11, 187. [CrossRef]

52. Wolpert, M.; Curtis-Tyler, K.; Edbrooke-Childs, J. A qualitative exploration of patient and clinician views on patient reported outcome measures in child mental health and diabetes services. Adm. Policy Mental Health Mental Health Serv. Res. 2016, 43, 309-315. [CrossRef] [PubMed]

53. Jacob, J.; Edbrooke-Childs, J.; Law, D.; Wolpert, M. Measuring what matters to patients: Using goal content to inform measure choice and development. Clin. Child Psychol. Psychiatry 2015, 22, 170-186. [CrossRef] [PubMed] 
54. National Institute for Clinical Excellence. Social Anxiety Disorder: Recognition, Assessment and Treatment. National Collaborating Centre for Mental Health: London, UK, 2013. Available online: http:/ / www.nice.org.uk/CG159 (accessed on 10 August 2017).

55. DeRubeis, R.J.; Cohen, Z.D.; Forand, N.R.; Fournier, J.C.; Gelfand, L.A.; Lorenzo-Luaces, L. The Personalized Advantage Index: Translating research on prediction into individualized treatment recommendations. A demonstration. PLoS ONE 2014, 9, e83875. [CrossRef] [PubMed] 